\title{
Universiteit
}

Leiden

The Netherlands

\section{Genetic risk factors for clozapine-induced neutropenia and agranulocytosis in a Dutch psychiatric population}

Weide, K. van der; Loovers, H.; Pondman, K.; Bogers, J.; Straaten, T. van der; Langemeijer, E.; ... ; Weide, J. van der

\section{Citation}

Weide, K. van der, Loovers, H., Pondman, K., Bogers, J., Straaten, T. van der, Langemeijer, E., ... Weide, J. van der. (2017). Genetic risk factors for clozapine-induced neutropenia and agranulocytosis in a Dutch psychiatric population. Pharmacogenomics Journal, 17(5), 471-478. doi:10.1038/tpj.2016.32

Version: $\quad$ Not Applicable (or Unknown)

License: $\quad$ Leiden University Non-exclusive license

Downloaded from: https://hdl.handle.net/1887/116136

Note: To cite this publication please use the final published version (if applicable). 


\title{
CONSENSUS ARTICLE
}

\section{Genetic risk factors for clozapine-induced neutropenia and agranulocytosis in a Dutch psychiatric population}

\author{
K van der Weide ${ }^{1}$, H Loovers $^{1,2}$, K Pondman $^{1}$, J Bogers ${ }^{3}$, T van der Straaten $^{4}$, E Langemeijer ${ }^{5}$, D Cohen ${ }^{6}$, J Commandeur and $^{7}$ \\ $\mathrm{J}$ van der Weide $\mathrm{l}^{1,2}$
}

Prescription of clozapine is complicated by the occurrence of clozapine-induced reduction of neutrophils. The aim of this study was to identify genetic risk factors in a population of 310 Dutch patients treated with clozapine, including 38 patients developing neutropenia and 31 patients developing agranulocytosis. NQO2 1541AA (NRH quinone oxidoreductase 2; protects cells against oxidative metabolites) was present at a higher frequency in agranulocytosis patients compared with control (23\% versus $7 \%$, $P=0.03$ ), as was $A B C B 1$ ( $A B C$-transporter-B1; drug efflux transporter) $3435 \pi$ (32\% versus $20 \%, P=0.05$ ). In patients developing neutropenia, $A B C B 13435 \pi$ and homozygosity for GSTT1 ${ }^{\text {null }}$ (glutathione-S-transferase; conjugates reactive clozapine metabolites into glutathione) were more frequent compared with control (34\% versus $20 \%, P=0.05$ and $31 \%$ versus $14 \%, P=0.03$ ), whereas GSTM $1^{\text {null }}$ was less frequent in these patients ( $31 \%$ versus $52 \%, P=0.03$ ). To investigate whether combinations of the identified genetic risk factors have a higher predictive value, should be confirmed in a larger case-control study.

The Pharmacogenomics Journal (2017) 17, 471-478; doi:10.1038/tpj.2016.32; published online 10 May 2016

\section{INTRODUCTION}

Clozapine is an atypical antipsychotic drug and is used with high efficacy in the treatment of refractory schizophrenia, defined as an insufficient treatment result after two consecutive antipsychotic trials. ${ }^{1,2}$ However, the use of clozapine is limited due to the risk of developing agranulocytosis, a potentially lethal drop in number of neutrophils, which occurs in about $0.4-0.8 \%$ of patients. ${ }^{3}$ Because clozapine-induced agranulocytosis $(\mathrm{CIA})$ has a fatality rate of 2.2-4.2\%, even while patients are monitored, ${ }^{3}$ its prescription is subject to strict regulations and requires regular control of white blood cells. The risk for CIA is highest within the first 18 weeks, although cases have been described in which CIA occurred years later. ${ }^{4,5}$ Physicians prescribing clozapine are confronted with several dilemmas. Should patients who oppose blood drawing be started on clozapine? Should patients with a decrease in neutrophils be continued on clozapine? How to proceed when a patient is prescribed clozapine and is having a fever? A better assessment of the individual risk could aid in decision making in clozapine treatment regimen and blood monitoring protocols. As twin studies have indicated a genetic component, the individual risk might be predicted by genetic polymorphisms. ${ }^{6,7}$ Several association studies have been performed in order to identify the genetic factors determining the susceptibility for $\mathrm{CIA}$ and neutropenia. Roge et al. ${ }^{8}$ suggested that the mechanism behind $\mathrm{CIA}$ and clozapine-induced neutropenia may be different.

The first associations between genetic markers and $\mathrm{CIA}$ were found for alleles of human leukocyte antigens ( $H L A s)$, implicating a role for the immune system in the pathogenesis of agranulocytosis. ${ }^{9}$ However, the initial studies on the association of $\mathrm{CIA}$ with HLA genes often concerned small numbers $(\sim 100$ patients in total), extended $H L A$ haplotypes and depended on ethnicity (reviewed in Chowdhury et al. ${ }^{10}$ ). The generally complex associations with HLA genes were suggested to originate from linkage disequilibrium with other polymorphisms located in nearby genes. ${ }^{11}$ Two candidate genes, located close to genes of the major histocompatibility complex are TNF- $a$ (tumor necrosis factor alpha) and Hsp70-2 (heat shock protein 70-2). Clozapine treatment is accompanied by an increase in TNF-a. ${ }^{12,13}$ Moreover, TNF alleles are in linkage disequilibrium with HLA haplotypes and one study showed an association between TNF microsatellites and CIA. ${ }^{14,15}$ Corzo et al. ${ }^{11,16}$ observed a linkage disequilibrium between the Hsp70-2 $8.5 \mathrm{~kb} / 9 \mathrm{~kb}$ Pstl polymorphic site and CIA-associated HLA haplotypes. Consequently, an association between this polymorphic site and CIA was observed. ${ }^{11}$

$\mathrm{CIA}$ is generally considered to be mediated by the oxidative metabolism of clozapine in neutrophils by the combination of $\mathrm{NAD}(\mathrm{P}) \mathrm{H}$-oxidase and myeloperoxidase (MPO). ${ }^{17,18}$, The reactive nitrenium ions and/or radicals formed have been shown to cause increased levels of oxidative stress and induction of apoptotic pathways in neutrophils of patients with $\mathrm{CIA} .{ }^{19}$ Both MPO and the NAD(P)H-oxidase subunit CYBA (cytochrome b-245 light chain) are genetically determined. The CYBA 640A $>G$ mutation is associated with lower $\mathrm{NAD}(\mathrm{P}) \mathrm{H}$-oxidase activity, and the $-463 \mathrm{G}>A$ mutation in the promotor site of MPO leads to lower MPO expression. A lower frequency would be expected in CIA patients, because these mutations will result in lower clozapine bioactivation. However, previous studies did not show statistically significant differences, possibly due to a small sample size (Table 5). ${ }^{20,21}$

\footnotetext{
1Department of Clinical Chemistry, St Jansdal Hospital, Harderwijk, The Netherlands; ${ }^{2}$ Psychiatric Hospital GGz Centraal, Dependance Meerkanten, Ermelo, The Netherlands; ${ }^{3}$ Mental Health Services Rivierduinen, Oegstgeest, The Netherlands; ${ }^{4}$ Department of Clinical Pharmacy and Toxicology, Leiden University Medical Center, Leiden, The Netherlands; ${ }^{5}$ Division of Medicinal Chemistry, Leiden/Amsterdam Center for Drug Research, Leiden University, Leiden, The Netherlands; ${ }^{6}$ Mental Health Services North-Holland North, Heerhugowaard, The Netherlands and ${ }^{7}$ AIMMS-Division of Molecular Toxicology, Department of Chemistry and Pharmaceutical Sciences, VU Amsterdam, Amsterdam, The Netherlands. Correspondence: Dr J van der Weide, Department of Clinical Chemistry, St Jansdal Hospital, PO Box 138,3840 AC Harderwijk, The Netherlands. 
Next to genetic polymorphisms at the level of clozapinebioactivating enzymes, also polymorphisms of protective enzymes involved in inactivation of reactive clozapine metabolites potentially determine susceptibility to CIA. Quinone oxidoreductases NQO1 and NQO2, which protect cells against oxidative metabolites, such as quinones and quinoneimines, are known to be strongly genetically determined. ${ }^{22,23}$ Their role in inactivation of reactive clozapine metabolites has not yet been demonstrated experimentally. A small association study on the role of NQO2 polymorphisms in CIA showed a higher frequency of the NQO2 $1541 \mathrm{~A}$ allele for $\mathrm{CIA}$ patients compared with control patients (Table 5). ${ }^{24}$ The nucleotide substitution $1541 G>A$ in the first intron is believed to affect a binding site for the myeloid zinc finger protein $\mathrm{MZF1} 1{ }^{24}$ which has a general role in the regulation of hematopoietic gene expression. ${ }^{25}$ This suggests that the resulting lower expression of $\mathrm{NQO} 2$ might increase the risk for $\mathrm{CIA}$. The role of polymorphism NQO1 C609T in CIA, which results in very low expression levels of NQO1, ${ }^{26}$ has not yet been studied.

Several glutathione S-transferases (GSTs) have been shown to catalyze the conjugation of reactive clozapine metabolites into glutathione. ${ }^{27}$ In humans, marked interindividual differences exist in the expression of class Alpha (GSTA), Mu (GSTM), Pi (GSTP) and Theta (GSTT) GSTs, ${ }^{28}$ due to genetic polymorphisms. In case of GSTM1 and GST11, part of the population completely lack the enzyme as a consequence of genetic deletions ('null genotypes'). Several studies have shown association of these GST-null genotypes with increased sensitivity to antitumor compounds ${ }^{29}$ and an increased susceptibility to adverse drug reactions. ${ }^{30}$ The presence of GSTA1 C-69T, one of the four linked base substitutions present in the GSTA1*B variant, results in a low hepatic expression in homozygous patients. ${ }^{31}$ Dependent of the substrate, the GSTP1 A313G mutation can result in altered catalytic efficiency, due to changes in the active site ${ }^{29}$ and was shown to be associated with a better response to platinum-based chemotherapy. ${ }^{32,33}$ Generally speaking, reduction in the ability to detoxify electrophilic reactive metabolites by GSTs may result in a higher risk for toxicity due to a higher exposure to the reactive metabolites.

Clozapine serum levels are influenced by polymorphisms in the P-glycoprotein (P-gp) transporter gene ABCB1 (MDR1). ${ }^{34,35}$ However, no direct relationship has been observed between clozapine serum levels and leukocyte counts. ${ }^{36}$ Interestingly, one case report described a CIA patient with a normal clozapine serum level, but an abnormally high clozapine level in neutrophils. ${ }^{37}$ Furthermore, one case report describes twin brothers who developed $\mathrm{CIA}$ and were heterozygous for both $A B C B 1$ C3435T and G2677T/A. ${ }^{6}$ These data suggest a link between $A B C B 1$ polymorphisms and the risk for $\mathrm{CIA}$, possibly by affecting clozapine levels in neutrophils, although further research is warranted.

The aim of this study was to investigate the above mentioned genetic risk factors for clozapine-induced neutropenia and agranulocytosis in a large Dutch psychiatric population prescribed with clozapine. Thirteen candidate gene polymorphisms were selected for investigation. The choice of polymorphism was based on reported association with $\mathrm{CIA}$ in other populations (CYBA A640G, HLA-DQB1 G6672C, Hsp70-2 G1276A, MPO G-463A (rs2333227) and NQO2 G1541A), putative role in CIA based on similarity with reported CIA-associated polymorphisms (NQO1 C609T (rs1800566) and TNF G-308A(rs1800629)) and putative role in clozapine transport ( $A B C B 1$ G2677T/A (rs2032582) and $A B C B 1$ C3435T (rs1045642)) and elimination (GSTA1 C-69T, GSTP1 A313G, and GSTT1 and GSTM1 gene deletion).

\section{MATERIALS AND METHODS}

Patients and setting

This retrospective study was conducted in the Dutch Psychiatric Hospital GGz Centraal location Meerkanten and in the Mental
Health Services Rivierduinen. According to national guidelines. Measurement of the number of leukocytes was performed just before the start of clozapine treatment, once a week in the first 18 weeks and once a month until the end of treatment. ${ }^{38}$ Patient selection occurred based on the criteria for CIA and neutropenia as described by the Food and Drug Administration. ${ }^{38,39}$ CIA patients were selected based on at least one neutrophil count $\leqslant 500 \mu^{-1}$. Neutropenia patients were selected on at least one neutrophil count between $500 \mu \mathrm{l}$ and $1500 \mu \mathrm{l}^{-1}$ or two neutrophil counts $<2000 \mathrm{\mu l}^{-1}$ during clozapine treatment. Patients were excluded when a neutrophil count $<2000 \mu^{-1}$ was recorded before the start of clozapine treatment.

Control patients were selected for prescription of clozapine for at least 1 year, no record of either neutrophil counts $<2000 \mathrm{\mu l}^{-1}$ or leukocyte counts $<4000 \mu^{-1}$. In all groups patients aged under 18 were excluded, as were patients for whom DNA samples could not be obtained. For patients of GGz Centraal, genotyping of CYP2D6 and CYP2C19 polymorphisms was performed routinely upon admission to the clinic and anonymized DNA samples were stored at $-70^{\circ} \mathrm{C}$ for research purposes and therefore for this study. For patients of Mental Health Services Rivierduinen, DNA samples are not routinely collected, therefore DNA was obtained after selection of the patients.

The condition of at least 1 year of clozapine use was justified by the fact that $80 \%$ of the total incidence of CIA occurs in the first 18 weeks of use, ${ }^{38,40}$ which is why in Europe patients are weekly monitored for blood cell counts during these first months. Less frequent cases of agranulocytosis were reported to occur during the first year, ${ }^{41,42}$ after which only incidental cases of CIA have been reported after up to 19 years of clozapine use. ${ }^{5}$

The Medical Research Ethics Committee in Amsterdam assessed the project and stated that it was not subject to further investigation under the Medical Research (Human Subjects) Act. The study has been approved by the research board (Innova) of Psychiatric Hospital GGz Centraal. Patients were not subjected to any procedures besides routine clinical practice and were informed on the use of data for research purposes. Data were excluded from research upon objection.

\section{Genotyping methods}

Thirteen polymorphisms were selected for analysis: $A B C B 1 \mathrm{G} 2677 T /$ A (rs2032582), ABCB1 C3435T (rs1045642), CYBA A640G, HLA-DQB1 G6672C, Hsp70-2 G1276A, MPO G-463A (rs2333227), NQO1 C609T (also known as NQO1*2, rs1800566), NQO2 G1541A, TNF G-308A (rs1800629), GSTA1 C-69T, GSTP1 A313G, and GST11 and GSTM1 gene deletion. The Hsp70-2 G1276A corresponds to the polymorphic Pstl site (8.5 and $9.0 \mathrm{~kb}$ allele) investigated in previous studies. ${ }^{43}$ Primer sequences, PCR extension and elongation conditions, restriction enzymes and length of obtained DNA fragments are shown in Table 1.

With exception of HLA-DQB1 and the GSTs, determinations were performed using allele-specific digestion of PCR products. Primer sequences and PCR extension and elongation conditions are shown in Table 1. HLA-DQB1 determination was performed using allele-specific reverse primers in combination with a common forward primer. For all polymorphisms except the GSTs, PCR reaction mixes contained 2-4 ng $\mathrm{\mu l}^{-1}$ DNA, $0.4 \mu \mathrm{M}$ of each primer, $0.2 \mathrm{mM}$ dNTPs, 0.04-0.1 U $\mathrm{Ll}^{-1}$ Thermoprime Plus DNA polymerase (Abgene House, Epsom, UK) and 1.0x ReddyMix PCR buffer. For NQO2 G1541A, a semi-nested PCR was performed using primers $\mathrm{HL} 1541 \mathrm{~F}+\mathrm{HL} 1541 \mathrm{R}$ on the PCR product obtained with primers HL1541F+HL1541R1. PCR products were digested and analyzed by gel electrophoresis. For MPO G-463A and ABCB1 G2677T/A, gel electrophoresis was performed after addition of SDS ( $1 \%$ final concentration) to the digestion products.

The presence of at least one GSTM1 and/or GSTT1 allele was determined as described by Arand et al. ${ }^{44}$ Briefly, $10 \mathrm{ng}$ of DNA 
Table 1. PCR primers and conditions and digestion patterns

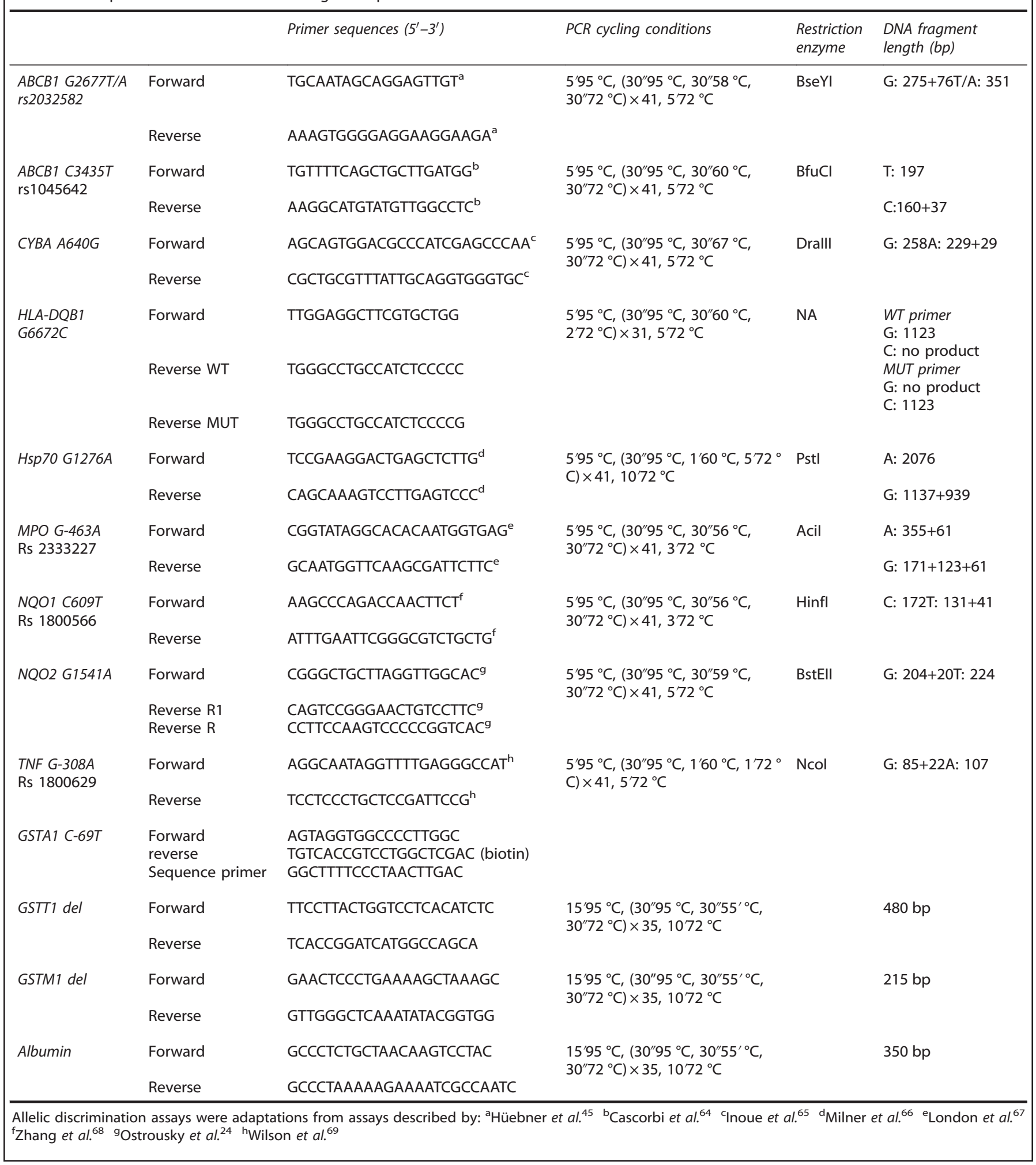

was taken to amplify representative sequences of the genes of GSTT1, GSTM1 and albumin (as reference gene). Hotstart PCR mastermix was used from Qiagen (Venlo, The Netherlands). The PCR products of the GSTT1 and GSTM1 were detected by agarose gel electrophoresis. The rs1695 genotype of GSTP1-1 (mutation A313G; lle105Val) was determined by allele-specific PCR using a predesigned Taqman assay (C__3237198_20) from Life Technologies (Nieuwerkerk a/d IJssel, The Netherlands) and analyzed on the 7500 real time PCR system (Life Technologies). The presence of GSTA1 C-69T was determined by pyrosequencing on a Pyrosequencer 96MA (Qiagen). Sequence to analyze was C/TCTTCTTCA and dispensation order was GTCGTCTCA. 
Table 2a. Patient information

\begin{tabular}{|c|c|c|c|c|c|c|}
\hline & Population (N) & Male/female & Age at lowest ANC & Clozapine dose & Plasma level & $\begin{array}{l}\text { Lifetime duration clozapine } \\
\text { treatment (months) }\end{array}$ \\
\hline Agranulocytose & 31 & 20 (65\%)/11 (35\%) & $46.2 \pm 14.8$ & $331 \pm 170$ & $354 \pm 344$ & $57.9 \pm 62.5$ \\
\hline Total & 310 & $206(66 \%) / 104(34 \%)$ & $44.2 \pm 17.0$ & $332 \pm 184$ & $264 \pm 157$ & $63.8 \pm 50.4$ \\
\hline
\end{tabular}

Table 2b. Co-medication

\begin{tabular}{|c|c|c|c|c|c|c|c|}
\hline & Number & Number & Average dose (mg) & Number & Average dose (mg) & Number & Average dose (mg) \\
\hline Neutropenia & 38 & $3(8 \%)$ & $900 \pm 361$ & $3(8 \%)$ & $433 \pm 153$ & $1(3 \%)$ & 15 \\
\hline Control & 241 & $24(10 \%)$ & $1283 \pm 457$ & $2(1 \%)$ & $400 \pm 0$ & $5(2 \%)$ & $12 \pm 12$ \\
\hline Total & 310 & $31(10 \%)$ & $1266 \pm 471$ & $6(2 \%)$ & $450 \pm 122$ & $6(2 \%)$ & $13 \pm 7$ \\
\hline
\end{tabular}

For $A B C B 1$ G2677T/A, no distinction could be made between $2677 T$ and 2677A; for simplicity the allele was classified as the more common $2677 T$ in this manuscript. ${ }^{45}$ Assays were validated by sequencing of one homozygous wild type, one homozygous mutant and one heterozygous sample (BaseClear, Leiden, The Netherlands). For HLA-DQB1, no homozygous 6672CC sample was available for sequencing.

\section{Statistics}

We calculated the necessary sample size (25 cases) based on a desired increased allele frequency in cases by 2.5 -fold in case of a frequency of 0.2 and a 1.6-fold increase of a frequency of 0.5 , assuming a 1:10 sample ratio of cases versus controls and a significance level of $a=0.05$ and $80 \%$ power $(\beta=0.2)$. Statistical analyses were performed using SPSS for Windows (SPSS version 15.0, Chicago, IL, USA). Cases were grouped according to neutrophil counts (see above). Subgroups were based on genotype; for all investigated polymorphisms differences in frequency of the three possible genotypes (homozygous for one or the other allele or heterozygous for both alleles) were analyzed, comparing frequencies in neutropenia and CIA patients with control patients and with each other. Statistical analyses for frequencies of genotypes were performed using Fisher exact probability test, showing two-tailed probability values. The strength of the associations between the polymorphism with neutropenia and $\mathrm{CIA}$ were expressed as odds ratios (ORs) with a 95\% confidence interval $(\mathrm{Cl})$.

\section{RESULTS}

A total of 310 patients treated with clozapine were included in this study; 31 patients exhibited CIA, 38 patients had neutropenia and 241 patients served as controls. Additional patient and clozapine use information and co-medication are presented in Tables $2 \mathrm{a}$ and $2 \mathrm{~b}$.

When comparing $\mathrm{CIA}$ patients with controls, as presented in Table 3, of the polymorphisms previously reported to be associated with CIA (CYBA 640, HLA-DQB1 G6672C, Hsp70-2 G1267A, NQO2 1541G and MPO G-463A) only NQO2 1541G had significantly different allele and genotype frequencies. Absolute numbers of different genotypes in the three different groups $(\mathrm{CI} A$, neutropenia and controls) are presented in Supplementary 1.
The NQO2 1541AA genotype, which is expected to result in low $\mathrm{NQO} 2$ expression, was present at a higher frequency in the case population (23\%) than in the control population $(7 \% ; P=0.004$; Table 3) and the NQO2 1541GG wild-type genotype was present in $53 \%$ of the control patients compared with only $29 \%$ in $\mathrm{CIA}$ patients. The odds ratio for developing $\mathrm{CIA}$ was 5.5 times higher for the homozygous mutant 1541AA genotype (Table 4).

A genetic test based on detection of NQO2 1541AA would have a sensitivity of $23 \%$ and a specificity of $97 \%$, with a negative predictive value of $90 \%$. For the other polymorphisms which were not yet studied in relation to CIA (ABCB1 G2677T, ABCB1 C3435T, NQO1 C609T, TNFa G-308A, GSTA1 -69T, GSTP1 313G, GSTT1 ${ }^{\text {null }}$, and GSTM $\left.1^{\text {null }}\right)$, the $A B C B 13435 T$ genotype was more frequent in CIA patients (32 versus $20 \%$ in controls; $P=0.05$; Table 3 ) and the wildtype $A B C B 13435 C C$ genotype was more frequent in controls ( $31 \%$ versus $16 \%$ in CIA patients). Homozygous mutant (3435TT) patients had a threefold higher chance on developing $\mathrm{CIA}$ (Table 3). In contrast, we observed a trend towards less $\mathrm{CIA}$ patients having the $A B C B 12677 \pi$ genotype (10\%) compared with controls $(20 \%, P=0.07)$. On the basis of these data, testing for $A B C B 13435 T T$ would have a sensitivity of $32 \%$ and a specificity of $80 \%$, with a negative predictive value of $90 \%$.

When comparing neutropenia patients with controls, again the risk of having neutropenia was about threefold higher in patients with the $A B C B 13435 T$ genotype; the $A B C B 13435 T$ genotype was more frequent in neutropenia patients (34\% versus $20 \%$ in controls) and the wild-type $A B C B 13435 C C$ genotype was more frequent in controls ( $31 \%$ versus $18 \%$ in neutropenia patients; $P=0.05$; Table 3). The GSTP1 $313 G$ G appears to be more frequent in neutropenia patients ( $25 \%$ versus $10 \%$ in controls), with an odds ratio of 2.5 , this is not statistically significant due to the small sample size. GSTT1 deficiency was more frequently observed in neutropenia patients ( $31 \%$ versus $14 \%$ in control patients; $P=0.03$; Table 3), with an odds ratio of 2.64 (Table 4). In contrast, $33 \%$ of neutropenia patients lacked the gene of GSTM1, compared to $53 \%$ in the control group. This difference does not appear to be statistically significant $(\mathrm{OR}=0.45)$.

\section{DISCUSSION}

Agranulocytosis is a very serious, life-threatening adverse effect of clozapine occurring in $0.4-0.8 \%$ of the patients. Although the 
Table 3. Allele and genotype frequencies for $\mathrm{CIA}$, neutropenia and control patients



Table 4. Odds ratios and $95 \%$ confidence intervals for $\mathrm{CIA}$, neutropenia and control patients

\begin{tabular}{|c|c|c|c|c|c|c|}
\hline & $O R^{\mathrm{a}}$ & $95 \% \mathrm{Cl}$ & $O R^{\mathrm{a}}$ & $95 \% \mathrm{Cl}$ & $O R^{\mathrm{a}}$ & $95 \% \mathrm{Cl}$ \\
\hline$A B C B 13435 T$ & 2.90 & $1.08-7.79$ & 3.13 & $1.01-9.70$ & 2.99 & $1.36-6.57$ \\
\hline CYBA $640 A$ & 0.44 & $0.16-1.26$ & 1.14 & $0.40-3.27$ & 0.70 & $0.33-1.51$ \\
\hline HLA-DQB1 $6672 G$ & 1.03 & $0.19-5.66$ & 0.71 & $0.16-3.20$ & 0.84 & $0.23-3.06$ \\
\hline NQO2 1541A & 0.30 & $0.04-2.33$ & 5.53 & $1.83-16.68$ & 1.72 & $0.69-4.31$ \\
\hline$M P O-463 A^{\mathrm{b}}$ & 1.85 & $0.93-3.69$ & 1.24 & $0.58-2.62$ & 1.54 & $0.90-2.64$ \\
\hline$T N F-308 A^{\mathrm{b}}$ & 0.87 & $0.41-1.85$ & 0.56 & $0.26-1.22$ & 0.71 & $0.24-1.77$ \\
\hline GSTA1 -69T & 0.53 & $0.16-1.68$ & 0.88 & $0.29-2.66$ & 0.66 & $0.29-1.57$ \\
\hline GSTP1 $313 G$ & 2.48 & $0.95-6.50$ & 1.19 & $0.30-4.76$ & 1.95 & $0.85-4.51$ \\
\hline GSTT1 $1^{\text {null }}$ & 2.64 & $1.19-5.86$ & 0.89 & $0.29-2.70$ & 1.73 & $0.88-3.41$ \\
\hline GSTM1 $1^{\text {null }}$ & 0.45 & $0.22-0.95$ & 0.85 & $0.40-1.79$ & 0.61 & $0.35-1.06$ \\
\hline
\end{tabular}

exact mechanism remains to be established, formation of reactive metabolites such as nitrenium ions are considered to have a role in development of $\mathrm{CIA} .{ }^{46,47}$ In addition, CIA is thought to be immune mediated. ${ }^{48}$ Therefore, variability in activity of the enzymes involved in bioactivation and inactivation as well as enzymes involved in immune reactions might be important factors determining interindividual susceptibility for these adverse drug reactions. In our study we tested whether polymorphisms in genes encoding such enzymes may serve as genetic predictors for $\mathrm{CIA}$ or neutropenia.

In the present study, a higher frequency of the NQO2 $1541 \mathrm{~A}$ allele was found for CIA patients, compared with control patients. Herewith, we confirm the findings of an Israeli study, with 98 clozapine users and $18 \mathrm{CIA}$ patients (Table 5, ref. 24). In contrast with Ostrousky's study, where all CIA patients were heterozygous for NQO2 1541G>A, also patients that were homozygous wild type or mutant were represented in the patients with CIA. Still, the allele frequencies in control and CIA patients are comparable, as are the numbers of $1541 \mathrm{~A}$ carriers in either group (47 and $51 \%$ in controls and 71 and $100 \%$ in CIA patients, this study versus Ostrousky et al. ${ }^{24}$ ). The NQO2 G1541A mutation results in disruption of the MZF1 binding site. ${ }^{24}$ MZF1 is specifically expressed in myeloid cells and essential for granulopoiesis. ${ }^{25}$ NQO2 mRNA expression was found to be lower in neutrophils of $\mathrm{CIA}$ patients than in control patients. ${ }^{24}$ Functional studies on the detoxification of clozapine metabolites by NQO2, however, are warranted to support the results.

Previously, the importance of NQO1 in neutrophiles was demonstrated using $\mathrm{NQO}^{-1-}$ mice, which were shown to be resistant to mitomycin-C-induced neutropenia. ${ }^{49}$ In humans, mutation NQO1 C609T is associated with reduced NQO1 activity. An association study in benzene-exposed adult Chinese workers showed NQO1 C609T is associated with greater risk of neutropenia, indicative for a protective role of NQO1 in human neutrophils. ${ }^{50}$ However, in the present study no association was found between NQO1 C609T and CIA, indicating that the enzyme function per se is not indicative of the development of CIA. The different substrate selectivities of NQO1 and NQO2 might explain their different contribution in protection against benzene and clozapine neutropenia.

A role for P-gp, a cell membrane-bound efflux pump encoded for by the ABCB1 gene, in clozapine transport across blood cell membranes has not yet been established. In the current study, the homozygous presence of $A B C B 13435 \pi$ seems to be a risk factor 
Table 5. Results from other studies control versus CIA

\begin{tabular}{|c|c|c|c|c|c|c|c|c|}
\hline & \multicolumn{2}{|c|}{ Allele frequency } & \multicolumn{2}{|c|}{ Homozygote frequency $^{\mathrm{a}}$} & \multirow[b]{2}{*}{ P-value } & \multirow[b]{2}{*}{$O R^{\mathrm{b}}$} & \multirow[b]{2}{*}{$95 \% \mathrm{Cl}$} & \multirow[b]{2}{*}{ Cases/controls } \\
\hline & Control & $C I A$ & Control & $C I A$ & & & & \\
\hline CYBA $640 A^{19}$ & 0.40 & 0.41 & 0.19 & 0.31 & 0.09 & 2.26 & $0.96-5.35$ & 78/75 \\
\hline$H L A-D Q B 16672 G^{58}$ & 0.99 & 0.89 & 0.98 & 0.78 & $<0.001$ & 0.06 & $0.01-0.26$ & $79 / 125$ \\
\hline Hsp70-2 $1267 G^{15}$ & 0.59 & 0.78 & 0.35 & 0.56 & 0.01 & 2.40 & $0.9-6.14$ & $32 / 43$ \\
\hline NQO2 $1541 A^{23}$ & 0.28 & 0.50 & 0.05 & 0.00 & $<0.001$ & ND & ND & $18 / 80$ \\
\hline MPO $-463 A^{\mathrm{b}, 19}$ & 0.20 & 0.22 & 0.03 & 0.10 & 0.11 & 1.12 & $0.59-2.14$ & $81 / 78$ \\
\hline$M P O-463 A^{b, 20}$ & 0.19 & 0.23 & 0.01 & 0.06 & 0.21 & 0.90 & $0.38-2.14$ & $31 / 77$ \\
\hline
\end{tabular}

Abbreviations: $\mathrm{Cl}$, confidence interval; $\mathrm{CIA}$, clozapine-induced agranulocytosis; ND, not determined; OR, odds ratio. ${ }^{\mathrm{a}}$ Regarding homozygous presence of indicated allele. ${ }^{\mathrm{b}}$ Regarding homo- or heterozygous presence of indicated allele.

for clozapine-induced decrease of neutrophils. The low frequency of the $A B C B 13435 C C$ genotype in CIA patients suggests a protective effect of $A B C B 13435 C C$ against lethal neutrophil diseases. Henning et al. ${ }^{51}$ showed that inhibitors of P-gp did not alter intracellular accumulation of clozapine in $\mathrm{HL}-60$ cells. ${ }^{51}$ However, the level of expression and activity of P-gp does depend on the type of blood cell. ${ }^{52}$ Also literature on $A B C B 1$ G2677A/T, resulting in the amino-acid substitution $\mathrm{A} 893 \mathrm{~S} / \mathrm{T}$, does not provide a definite conclusion on the effect of this polymorphism on expression or function of the transporter in vivo. Depending on patient groups or cell type, the $A B C B 12677 G$ allele was associated with increased, decreased or similar transcription and/or expression levels. ${ }^{53-57}$ Both the $A B C B 1$ 2677GG genotype and the $A B C B 1$ $3435 C C$ were associated with reduced serum levels of clozapine, $A B C B 13435 C C$ showing the most prominent effects. ${ }^{34,35}$ Clozapine concentrations in neutrophils could well be increased for patients homozygous for $A B C B 12677 G G$ or $3435 C C$, despite lower serum levels. A case report describing a normal clozapine serum level, but abnormally high clozapine levels in neutrophils in a CIA patient does indicate a role for clozapine transporters in CIA. ${ }^{37}$ In literature no direct relationship has been observed between clozapine serum levels and leukocyte counts, most likely because cellular uptake, bioactivation and inactivation are important factors.

ABCB1 G2677T and C3435T are reported to be genetically linked, ${ }^{58}$ as was the case in our study (data not shown). However, although we find comparable allele frequencies in control patients, the $3435 T$ allele was more frequent in $\mathrm{CIA}$, whereas the $2677 T$ frequency was lower. In a previous study, mutation $A B C B 1$ C3435T, but not G2677T, was found to be related to neutropenia induced by the antitumor agent amrubicin in lung cancer patients. ${ }^{59}$ These results and our results suggest that the mutation C3435T might have a more prominent effect on ABCB1 activity than G2677T.

For CYBA 640 and MPO-463 our results do not notably differ from those obtained in another study (Table 5). ${ }^{20}$ However, for Hsp70-2 1267 we could not reproduce the results obtained by Corzo et al. ${ }^{16}$ (Table 5): although we did find an OR that approximates the reported one, our findings do not reach statistical significance. The small overall sample size of the former study and the limited number of cases in both studies are likely the cause of this discrepancy.

GSTM1, GSTA1 and GSTP1 were shown to be involved in glutathione conjugation of the nitrenium ion of clozapine, GSTP1 having the highest activity. ${ }^{27}$ In the present study, GSTP1 polymorphism was not associated with either CIA or neutropenia, which can be explained by the fact that the mutation only has a minor effect on inactivation of the reactive nitrenium ion of clozapine. $^{60}$ Although GSTT1 appeared to be inactive in inactivation of this reactive metabolite, ${ }^{27}$ an overrepresentation of GSTI1 $1^{\text {null }}$ genotype in patients with clozapine-induced neutropenia was found in this study. Deficiency of GSTM1 was less frequent in patient with neutropenia, therefore seems a protective factor. Deficiency of GSTM1 was found previously to cause resistance against acetaminophen-induced hepatotoxicity in mice, by disrupting a cellular pathway involved in cytotoxicity. ${ }^{61}$ Whether a similar mechanism might be applicable in neutrophiles remains to be established.

HLA-DQB1 $6672 \mathrm{C}$ has been associated with CIA previously, ${ }^{62}$ and even the pharmacogenetic test PGXPredict:CLOZAPINE (PGxHealth, New Haven, USA, discontinued in March 2011) was based on this polymorphism. Furthermore, in a recent GWAS study on 98 CIA cases, an amino-acid substitution in HLA-DQB1 that is in linkage disequilibrium with the 6672C SNP was found to be associated with CIA. ${ }^{63}$ The results of the present study did not confirm these associations, (Table 5) although the overall frequencies of both cases and controls combined were comparable $\left(9 \%{ }^{15}\right.$ versus $8 \%$ in our study), the previously reported frequency of the marker in cases versus control (22 versus $2 \%$, Table 5) $)^{15}$ differs notably from our findings (10 versus $7 \%$ ).

It is conceivable that, for example, an aberrant transport of clozapine, resulting in increased intracellular levels, poses a much greater risk for $\mathrm{CIA}$ if combined with an aberrant reaction of neutrophils to stress. However, we could not find such combinations in our study since our sample size does not allow for finding combined genetic predictors. Of note, with a prevalence of $0.4-0.8 \%$ for $\mathrm{ClA}$ and $3 \%$ for neutropenia, it is challenging to include more cases. Further limitations of this study are the variations in dose, co-medication and treatment duration. Which are related to the retrospective structure of the study. Dose variations were previously shown not to influence the occurrence of CIA. ${ }^{36}$ Treatment duration was used as a selection criterion for control patients. Co-medication was limited (Table $2 \mathrm{~b}$ ) and did not vary between groups.

In conclusion, this study describes 31 patients who developed clozapine-induced agranulocytosis and 38 patients who developed neutropenia in a group of 310 clozapine users. The most significant association with $\mathrm{CIA}$ was found with mutation NQO2 G1541A, making it one of the candidate markers for the prediction of $\mathrm{CIA}$, with in this study a specificity of $97 \%$ and a sensitivity of $23 \%$. Furthermore, an association was found between $\mathrm{CIA}$ and a P-gp transporter polymorphism (ABCB1 3435T) for the first time. So far the predictive value of individual genetic polymorphisms is not strong enough to predict $\mathrm{ClA}$ with high accuracy. Therefore most likely combinations of risk factors, such as increased cellular uptake, high bioactivation, low bioinactivation, and immunological factors are required to result in CIA. Much larger association studies, allowing the study of combinations of genetic markers and risk factors, will be required to identify the high-risk combinations for clozapine-induced agranulocytosis and neutropenia. 


\section{CONFLICT OF INTEREST}

The authors declare no conflict of interest.

\section{ACKNOWLEDGMENTS}

We acknowledge and appreciate the support in database mining by $\mathrm{D}$ van de Glind, $R$ Herben and B Pijl (GGz Centraal) and B Scholten and $M$ de Lassaquère-van Renselaar (St Jansdal Hospital). We also appreciate the work performed by the DNA technicians.

\section{REFERENCES}

1 Kane J, Honigfeld G, Singer J, Meltzer H. Clozapine for the treatment-resistant schizophrenic. A double-blind comparison with chlorpromazine. Arch Gen Psychiatry 1988; 45: 789-796.

2 Buchanan RW. Clozapine: efficacy and safety. Schizophr Bull 1995; 21: 579-591.

3 Cohen D, Bogers JP, van Dijk D, Bakker B, Schulte PF. Beyond white blood cell monitoring: screening in the initial phase of clozapine therapy. J Clin Psychiatry 2012; 73: 1307-1312.

4 Schulte P. Risk of clozapine-associated agranulocytosis and mandatory white blood cell monitoring. Ann Pharmacother 2006; 40: 683-688.

5 Cohen D, Monden M. White blood cell monitoring during long-term clozapine treatment. Am J Psychiatry 2013; 170: 366-369.

6 Yagcioglu AE, Ilhan BC, Goktas MT, Babaoglu MO, Uz E, Yazici MK. Agranulocytosis related to clozapine in monozygotic twins and association with allelic variants of multidrug resistance gene MDR1. J Clin Psychopharmacol 2011; 31: 247-249.

7 Horacek JL. Clozapine-induced concordant agranulocytosis in monozygotic twins. Int J Psychiatry Clin Pract 2001; 5: 71-73.

8 Roge R, Moller BK, Andersen CR, Correll CU, Nielsen J. Immunomodulatory effects of clozapine and their clinical implications: what have we learned so far? Schizophr Res 2012; 140: 204-213.

9 Lieberman JA, Yunis J, Egea E, Canoso RT, Kane JM, Yunis EJ. HLA-B38, DR4, DQw3 and clozapine-induced agranulocytosis in Jewish patients with schizophrenia. Arch Gen Psychiatry 1990; 47: 945-948.

10 Chowdhury NI, Remington G, Kennedy JL. Genetics of antipsychotic-induced side effects and agranulocytosis. Curr Psychiatry Rep 2011; 13: 156-165.

11 Corzo D, Yunis JJ, Salazar M, Lieberman JA, Howard A, Awdeh Z et al. The major histocompatibility complex region marked by HSP70-1 and HSP70-2 variants is associated with clozapine-induced agranulocytosis in two different ethnic groups. Blood 1995 15; 86: 3835-3840.

12 Hinze-Selch D, Deuschle M, Weber B, Heuser I, Pollmacher T. Effect of coadministration of clozapine and fluvoxamine versus clozapine monotherapy on blood cell counts, plasma levels of cytokines and body weight. Psychopharmacology (Berl) 2000; 149: 163-169.

13 Kluge M, Schuld A, Schacht A, Himmerich H, Dalal MA, Wehmeier PM et al. Effects of clozapine and olanzapine on cytokine systems are closely linked to weight gain and drug-induced fever. Psychoneuroendocrinology 2009; 34: 118-128.

14 Jongeneel CV, Briant L, Udalova IA, Sevin A, Nedospasov SA, Cambon-Thomsen A. Extensive genetic polymorphism in the human tumor necrosis factor region and relation to extended HLA haplotypes. Proc Natl Acad Sci USA 1991; 88: 9717-9721.

15 Turbay D, Lieberman J, Alper CA, Delgado JC, Corzo D, Yunis JJ et al. Tumor necrosis factor constellation polymorphism and clozapine-induced agranulocytosis in two different ethnic groups. Blood 1997; 89: 4167-4174.

16 Corzo D, Yunis JJ, Yunis EJ, Howard A, Lieberman JA. HSP70-2 9.0 kb variant is in linkage disequilibrium with the HLA-B and DRB1* alleles associated with clozapine-induced agranulocytosis. J Clin Psychiatry 1994; 55 (Suppl B): 149-152.

17 Babior BM, Lambeth JD, Nauseef W. The neutrophil NADPH oxidase. Arch Biochem Biophys 2002; 397: 342-344.

18 Frimat B, Gressier B, Odou P, Brunet C, Dine T, Luycky M et al. Metabolism of clozapine by human neutrophils: evidence for a specific oxidation of clozapine by the myeloperoxidase system with inhibition of enzymatic chlorination cycle. Fundam Clin Pharmacol 1997; 11: 267-274.

19 Fehsel K, Loeffler S, Krieger K, Henning U, Agelink M, Kolb-Bachofen V et al. Clozapine induces oxidative stress and proapoptotic gene expression in neutrophils of schizophrenic patients. J Clin Psychopharmacol 2005; 25: 419-426.

20 Mosyagin I, Dettling M, Roots I, Mueller-Oerlinghausen B, Cascorbi I. Impact of myeloperoxidase and NADPH-oxidase polymorphisms in drug-induced agranulocytosis. J Clin Psychopharmacol 2004; 24: 613-617.

21 Dettling M, Sachse C, Muller-Oerlinghausen B, Roots I, Brockmoller J, Rolfs A et al. Clozapine-induced agranulocytosis and hereditary polymorphisms of clozapine metabolizing enzymes: no association with myeloperoxidase and cytochrome P4502D6. Pharmacopsychiatry 2000; 33: 218-220.

22 Vasiliou V, Ross D, Nebert DW. Update of the NAD(P)H:quinone oxidoreductase (NQO) gene family. Hum Genomics 2006; 2: 329-335.
23 Dinkova-Kostova AT, Talalay P. NAD(P)H:quinone acceptor oxidoreductase 1 (NQO1), a multifunctional antioxidant enzyme and exceptionally versatile cytoprotector. Arch Biochem Biophys 2010; 501: 116-123.

24 Ostrousky O, Meged S, Loewenthal R, Valevski A, Weizman A, Carp H et al. NQO2 gene is associated with clozapine-induced agranulocytosis. Tissue Antigens 2003; 62: 483-491.

25 Tenen DG, Hromas R, Licht JD, Zhang DE. Transcription factors, normal myeloid development, and leukemia. Blood 1997; 90: 489-519.

26 Siegel D, McGuinness SM, Winski SL, Ross D. Genotype-phenotype relationships in studies of a polymorphism in $\mathrm{NAD}(\mathrm{P}) \mathrm{H}$ :quinone oxidoreductase 1. Pharmacogenetics 1999; 9: 113-121.

27 Dragovic S, Boerma JS, Bergen L, Vermeulen NP, Commandeur JN. Role of human glutathione S-transferases in the inactivation of reactive metabolites of clozapine. Chem Res Toxicol 2010; 23: 1467-1476.

28 Hayes JD, Strange RC. Glutathione S-transferase polymorphisms and their biological consequences. Pharmacology 2000; 61: 154-166.

29 Di Pietro G, Magno LA, Rios-Santos F. Glutathione S-transferases: an overview in cancer research. Expert Opin Drug Metab Toxicol 2010; 6: 153-170.

30 Lucena Ml, Andrade RJ, Martinez C, Ulzurrun E, Garcia-Martin E, Borraz Y et al. Glutathione S-transferase $\mathrm{m} 1$ and $\mathrm{t} 1$ null genotypes increase susceptibility to idiosyncratic drug-induced liver injury. Hepatology 2008; 48: 588-596.

31 Coles BF, Kadlubar FF. Human alpha class glutathione S-transferases: genetic polymorphism, expression, and susceptibility to disease. Methods Enzymol 2005; 401: 9-42.

32 Stoehlmacher J, Park DJ, Zhang W, Groshen S, Tsao-Wei DD, Yu MC et al. Association between glutathione S-transferase P1, T1, and M1 genetic polymorphism and survival of patients with metastatic colorectal cancer. J Natl Cancer Inst 2002; 94: 936-942.

33 Maggini V, Buda G, Galimberti S, Conidi E, Giuliani N, Morabito F et al. Response to chemotherapy and tandem autologous transplantation of multiple myeloma patients and GSTP1 and TYMS polymorphisms. Leuk Res 2008; 32: 49-53.

34 Consoli G, Lastella M, Ciapparelli A, Catena DM, Ciofi L, Guidotti E et al. ABCB1 polymorphisms are associated with clozapine plasma levels in psychotic patients. Pharmacogenomics 2009; 10: 1267-1276.

35 Jaquenoud SE, Knezevic B, Morena GP, Harenberg S, Oneda B, Crettol S et al. $A B C B 1$ and cytochrome P450 polymorphisms: clinical pharmacogenetics of clozapine. J Clin Psychopharmacol 2009; 29: 319-326.

36 Centorrino F, Baldessarini RJ, Flood JG, Kando JC, Frankenburg FR. Relation of leukocyte counts during clozapine treatment to serum concentrations of clozapine and metabolites. Am J Psychiatry 1995; 152: 610-612.

37 Bergemann N, Abu-Tair F, Aderjan R, Kopitz J. High clozapine concentrations in leukocytes in a patient who developed leukocytopenia. Prog Neuropsychopharmacol Biol Psychiatry 2007; 31: 1068-1071.

38 Schulte PFJ, Bakker B, Bogers J, Cohen D, vanDijk D. Guideline for the use of Clozapine. Dutch Clozapine Collaboration Group 2013; 5 February 2013; accessed on 10 December 2015. available from: http://www.clozapinepluswerkgroep.nl/ publicaties/richtlijn-voor-het-gebruik-van-clozapine/

39 Novartis. Clozaril. 14 January 2004; accessed on 14 January 2016. available from: http://www.fda.gov/ohrms/dockets/dailys/02/may02/053002/02p-0247-cp0000104-attachment-b-vol1.pdf

40 Verbelen $M$, Lewis CM. How close are we to a pharmacogenomic test for clozapine-induced agranulocytosis? Pharmacogenomics 2015; 16: 915-917.

41 Alvir JM, Lieberman JA, Safferman AZ, Schwimmer JL, Schaaf JA. Clozapineinduced agranulocytosis. Incidence and risk factors in the United States. N Engl J Med 1993; 329: 162-167.

42 Atkin K, Kendall F, Gould D, Freeman H, Liberman J, O'Sullivan D. Neutropenia and agranulocytosis in patients receiving clozapine in the UK and Ireland. $\mathrm{Br} J \mathrm{Psy}$ chiatry 1996; 169: 483-488.

43 Milner CM, Campbell RD. Structure and expression of the three MHC-linked HSP70 genes. Immunogenetics 1990; 32: 242-251.

44 Arand M, Muhlbauer R, Hengstler J, Jager E, Fuchs J, Winkler L et al. A multiplex polymerase chain reaction protocol for the simultaneous analysis of the glutathione S-transferase GSTM1 and GSTT1 polymorphisms. Anal Biochem 1996; 236: $184-186$

45 Huebner C, Petermann I, Browning BL, Shelling AN, Ferguson LR. Triallelic single nucleotide polymorphisms and genotyping error in genetic epidemiology studies: MDR1 (ABCB1) G2677/T/A as an example. Cancer Epidemiol Biomarkers Prev 2007; 16: $1185-1192$.

46 Liu ZC, Uetrecht JP. Clozapine is oxidized by activated human neutrophils to a reactive nitrenium ion that irreversibly binds to the cells. J Pharmacol Exp Ther 1995; 275: 1476-1483.

47 Williams DP, Pirmohamed M, Naisbitt DJ, Maggs JL, Park BK. Neutrophil cytotoxicity of the chemically reactive metabolite(s) of clozapine: possible role in agranulocytosis. J Pharmacol Exp Ther 1997; 283: 1375-1382. 
48 Tesfa D, Keisu M, Palmblad J. Idiosyncratic drug-induced agranulocytosis: possible mechanisms and management. Am J Hematol 2009; 84: 428-434.

49 Adikesavan AK, Barrios R, Jaiswal AK. In vivo role of $\mathrm{NAD}(\mathrm{P}) \mathrm{H}$ :quinone oxidoreductase 1 in metabolic activation of mitomycin $\mathrm{C}$ and bone marrow cytotoxicity. Cancer Res 2007; 67: 7966-7971.

50 Rothman N, Smith MT, Hayes RB, Traver RD, Hoener B, Campleman S et al. Benzene poisoning, a risk factor for hematological malignancy, is associated with the NQO1 609C--> T mutation and rapid fractional excretion of chlorzoxazone. Cancer Res 1997; 57: 2839-2842.

51 Henning U, Loffler S, Krieger K, Klimke A. Uptake of clozapine into HL-60 promyelocytic leukaemia cells. Pharmacopsychiatry 2002; 35: 90-95.

52 Klimecki WT, Futscher BW, Grogan TM, Dalton WS. P-glycoprotein expression and function in circulating blood cells from normal volunteers. Blood 1994; 83: 2451-2458.

53 Rebecchi IM, Rodrigues AC, Arazi SS, Genvigir FD, Willrich MA, Hirata MH et al. $A B C B 1$ and $A B C C 1$ expression in peripheral mononuclear cells is influenced by gene polymorphisms and atorvastatin treatment. Biochem Pharmacol 2009; 77: 66-75.

54 Haenisch S, Zimmermann U, Dazert E, Wruck CJ, Dazert P, Siegmund W et al. Influence of polymorphisms of $A B C B 1$ and $A B C C 2$ on $m R N A$ and protein expression in normal and cancerous kidney cortex. Pharmacogenomics J 2007; 7: 56-65.

55 Mosyagin I, Runge U, Schroeder HW, Dazert E, Vogelgesang S, Siegmund W et al. Association of $A B C B 1$ genetic variants $3435 C>T$ and $2677 \mathrm{G}>T$ to $A B C B 1$ mRNA and protein expression in brain tissue from refractory epilepsy patients. Epilepsia 2008; 49: 1555-1561.

56 Oselin K, Mrozikiewicz PM, Pahkla R, Roots I. Quantitative determination of the human MRP1 and MRP2 mRNA expression in FACS-sorted peripheral blood CD4+, CD8+, CD19+, and CD56+ cells. Eur J Haematol 2003; 71: 119-123.

57 Song P, Lamba JK, Zhang L, Schuetz E, Shukla N, Meibohm B et al. G2677T and C3435T genotype and haplotype are associated with hepatic ABCB1 (MDR1) expression. J Clin Pharmacol 2006; 46: 373-379.

58 Onnie CM, Fisher SA, Pattni R, Sanderson J, Forbes A, Lewis CM et al. Associations of allelic variants of the multidrug resistance gene (ABCB1 or MDR1) and inflammatory bowel disease and their effects on disease behavior: a case-control and meta-analysis study. Inflamm Bowel Dis 2006; 12: 263-271.
59 Takakuwa O, Oguri T, Uemura T, Kunii E, Nakao M, Hijikata $\mathrm{H}$ et al. ABCB1 polymorphism as a predictive biomarker for amrubicin-induced neutropenia. Anticancer Res 2014; 34: 3517-3522.

60 Dragovic S, Venkataraman H, Begheijn S, Vermeulen NP, Commandeur JN. Effect of human glutathione S-transferase hGSTP1-1 polymorphism on the detoxification of reactive metabolites of clozapine, diclofenac and acetaminophen. Toxicol Lett 2014; 224: 272-281.

61 Arakawa S, Maejima T, Fujimoto K, Yamaguchi T, Yagi M, Sugiura T et al. Resistance to acetaminophen-induced hepatotoxicity in glutathione S-transferase $\mathrm{Mu}$ 1-null mice. J Toxicol Sci 2012; 37: 595-605.

62 Athanasiou MC, Dettling M, Cascorbi I, Mosyagin I, Salisbury BA, Pierz KA et al. Candidate gene analysis identifies a polymorphism in HLA-DQB1 associated with clozapine-induced agranulocytosis. J Clin Psychiatry 2011; 72: 458-463.

63 Goldstein Jl, Jarskog LF, Hilliard C, Alfirevic A, Duncan L, Fourches D et al. Clozapine-induced agranulocytosis is associated with rare HLA-DQB1 and HLA-B alleles. Nat Commun 2014; 5: 4757.

64 Cascorbi I, Gerloff T, Johne A, Meisel C, Hoffmeyer S, Schwab M et al. Frequency of single nucleotide polymorphisms in the P-glycoprotein drug transporter MDR1 gene in white subjects. Clin Pharmacol Ther 2001; 69: 169-174.

65 Inoue N, Kawashima S, Kanazawa K, Yamada S, Akita H, Yokoyama M. Polymorphism of the NADH/NADPH oxidase p22 phox gene in patients with coronary artery disease. Circulation 1998; 97: 135-137.

66 Milner CM, Campbell RD. Polymorphic analysis of the three MHC-linked HSP70 genes. Immunogenetics 1992; 36: 357-362.

67 London SJ, Lehman TA, Taylor JA. Myeloperoxidase genetic polymorphism and lung cancer risk. Cancer Res 1997; 57: 5001-5003.

68 Zhang J, Schulz WA, Li Y, Wang R, Zotz R, Wen D et al. Association of NAD $(P) H$ : quinone oxidoreductase 1 (NQO1) C609T polymorphism with esophageal squamous cell carcinoma in a German Caucasian and a northern Chinese population. Carcinogenesis 2003; 24: 905-909.

69 Wilson AG, di Giovine FS, Blakemore Al, Duff GW. Single base polymorphism in the human tumour necrosis factor alpha (TNF alpha) gene detectable by $\mathrm{Ncol}$ restriction of PCR product. Hum Mol Genet 1992; 1: 353.

Supplementary Information accompanies the paper on the The Pharmacogenomics Journal website (http://www.nature.com/tpj) 